\title{
Trichoscopy of scalp lesions in patient with erythroderma
}

\section{Selma El Kadiri, Zakia Douhi, Rhizlane Chaoui, Sara Elloudi, Hanane Baybay, Fatima-Zahra Mernissi}

Department of Dermatology, CHU Hassan II , Fez, Morocco

Corresponding author: Dr. Selma El Kadiri, E-mail: dermatologie90@gmail.com

Sir,

Scalp is a common location of autoimmune bullous diseases [1]. We report a case of 52-year old woman presented with erythroderma associated with pruriginous erythema in the scalp. Dermatological examination revealed erythema and scaling affecting $60 \%$ of the scalp (Fig. 1). Dermoscopy showed white diffuse scaling, extravasations and polymophic vessels. The vascular pattern were dotted, linear serpentine and circular (Fig. 2). Histopathological examination of biopsy specimens showed blister in the superficial epidermis and spongiosis in the stratum granulosum. Direct immunoflurescence demonstrated the presence of intercellular $\operatorname{IgG}$ and $\mathrm{C} 3$ within the superficial layers of the epidermis. Features were consistent with a foliaceus pemphigus and the association of oral corticotherapy and rituximab was adopted for this patient. Remission was achieved after one cycle of rituximab with a mean delay of 3 months.

Trichoscopy in a noninvasive tool for assessing scalp dermatosis [1]. They are only few reports on the interest of trichoscopy in pemphigus [1-3]. Trichoscopy of scalp in foliaceus pemphigus found white diffuse scaling which can occurs also in psoriasis, allergic dermatitis and xerosis [1]. The vascular pattern may be represented by dotted, circular and serpentine vessels. The last one pattern can occur also in discoid lupus erythematous [4]. We propose to use trichoscopy as an additional argument to make a spresumptive diagnosis of foliaceus pemphigus specially in case of erythroderma even if confirmation is by histology and direct immunoflurescence.

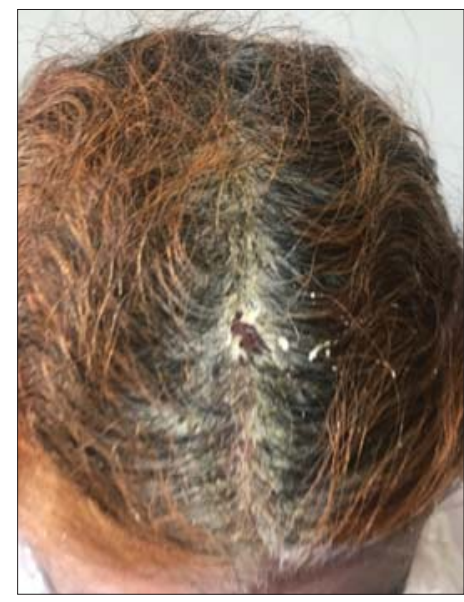

Figure 1: Clinical image showing erythema and scaling affecting $60 \%$ of the scalp.

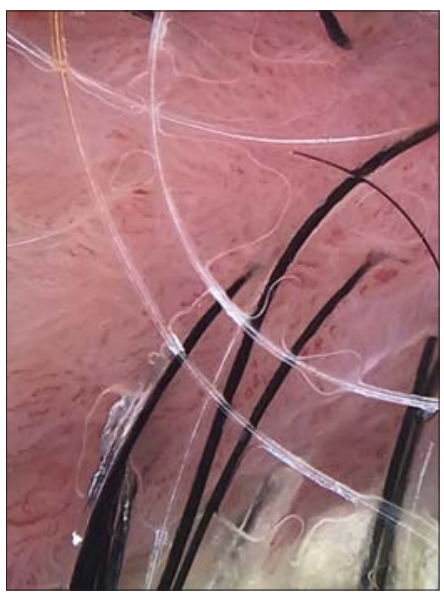

Figure 2: Dermoscopy showed white diffuse scaling, extravasations and polymophic vessels.

\section{Consent}

The examination of the patient was conducted according to the Declaration of Helsinki principles.

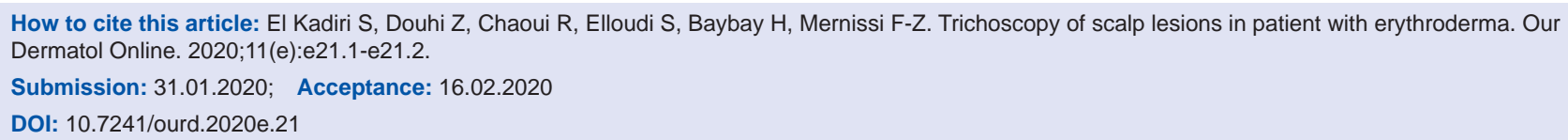


The authors certify that they have obtained all appropriate patient consent forms. In the form the patient(s) has/have given his/her/their consent for his/her/their images and other clinical information to be reported in the journal. The patients understand that their names and initials will not be published and due efforts will be made to conceal their identity, but anonymity cannot be guaranteed.

\section{REFERENCES}

1. Sar-Pomian M. Trichoscopy - a useful tool in the preliminary differential diagnosis of autoimmune bullous diseases. Int J
Dermatol. 2017;56:996-1002.

2. Pirmez R. Acantholytic hair casts: a dermoscopic sign of pemphigus vulgaris of the scalp. Int J Trichology. 2012;4:172-3.

3. Sar-Pomian M, Kurzeja M, Rudnicka L, Olszewska M. The value of trichoscopy in the differential diagnosis of scalp lesions in pemphigus vulgaris and pemphigus foliaceus. An Bras Dermatol. 2014;89:1007-12.

4. Rudnicka L, Olszewska M, Rakowska A. Atlas of Trichoscopy: Dermoscopy in Hair and Scalp Disease. London: Springer, 2012.

Copyright by Selma El Kadiri, et al. This is an open-access article distributed under the terms of the Creative Commons Attribution License, which permits unrestricted use, distribution, and reproduction in any medium, provided the original author and source are credited.

Source of Support: Nil, Conflict of Interest: None declared. 